\title{
Systemic Liquidity and the Composition of Foreign Investment: Theory and Empirical Evidence
}

\author{
Itay Goldstein ${ }^{1}$, Assaf Razin ${ }^{2}$, and Hui Tong ${ }^{34}$
}

February 12, 2007

${ }^{1}$ Finance Department, The Wharton School, University of Pennsylvania, Philadelphia, PA 19104; itayg@wharton.upenn.edu.

${ }^{2}$ Cornell and Tel-Aviv Universities. Department of Economics, Cornell University, Ithaca, NY 14583; razin@post.tau.ac.il

${ }^{3}$ Research Department, IMF, 700 19th St, Washington DC, 20431; htong@imf.org.

${ }^{4}$ We acknowledge insightful comments by Rui Albuquerque, Samuel Bentolila, Robert Flood, Olivier Jeanne, Enrique Mendoza, Rafael Repullo and participants at the IMF Research Department's Junior Economist Workshop. This paper represents the views of the authors and should not be thought to represent those of the International Monetary Fund. 


\begin{abstract}
This paper studies the impact of liquidity on investors' choice between Foreign Direct Investment (FDI) and Foreign Portfolio Investment (FPI). As argued in Goldstein and Razin (2006), this choice could be influenced by the trade off between management efficiency and liquidity effects. Here we extend their model by assuming liquidity shocks to individual investors are triggered by aggregate liquidity shocks. A key prediction then is that countries with higher probability of aggregate liquidity crises will be the source of more FPI and less FDI. To test this hypothesis, we therefore apply a dynamic panel model to examine the variation of FPI relative to FDI for 140 source countries from 1990 to 2004. Our key variable is the probability, estimated from Probit models, of liquidity shocks, as proxied by episodes of negative purchase of external assets. It turns out that liquidity shocks have strong effects on the composition of foreign investment, as predicted by our model. Moreover, capital market opacity in source country accelerates the effect of the probability of liquidity shock on the FPI/FDI composition. We repeat this analysis using real interest rate hike or real exchange rate depreciation as an alternative indicator of a liquidity crisis, and get similar results.
\end{abstract}




\section{Introduction}

International equity flows are the main feature of the recent globalization of capital markets both in developing and in developed economies. These flows take two major forms: Foreign Direct Investments (FDI) and Foreign Portfolio Investments (FPI). Despite the prominence of these two forms of investment, not much is known about the factors that guide international investors in choosing between them.

In a recent paper, Goldstein and Razin (2006) propose a new model to analyze the decision of international investors between investing in the form of FDI or in the form of FPI. Their model highlights a key difference between the two types of investment: FDI investors are in effect the managers of the firms under their control; whereas FPI investors delegate decisions to managers. Consequently, direct investors are more informed than portfolio investors regarding changes in the prospects of their projects. This information enables them to manage their projects more efficiently. This informational advantage, however, comes with a cost. If investors need to sell their investments before maturity because of liquidity shocks, the price they can get will be lower when buyers know that they have more information on the economic fundamentals of the investment project.

A key implication of the Goldstein and Razin (2006) model is that the choice between FDI and FPI will be linked to the likelihood with which investors expect to get a liquidity shock. A problem with taking the model to the data, however, is that it assumes that liquidity shocks to individual investors are completely idiosyncratic, i.e., there is no correlation between the realization of a liquidity shock for one investor and that for other investors. Idiosyncratic liquidity shocks, in turn, are not observable to econometricians, and thus this aspect of the model cannot be easily tested.

In this paper, we extend the Goldstein and Razin (2006) model by making the more realistic assumption that liquidity shocks to individual investors are triggered by some aggregate liquidity shock. We are trying to capture the idea that individual investors are forced to sell their investments early particularly at times when there are aggregate liquidity problems. In those times, some individual investors have deeper pockets than others, and thus are less exposed to the liquidity issues. Thus, once an aggregate liquidity shock occurs, some individual investors will need to sell, but they will get a low price because buyers do not know if they have deep pockets and sell because of adverse information or because they are truly affected by the aggregate liquidity crisis.

The key prediction of the model is that countries that have a high probability of an aggregate 
liquidity crisis will be the source of more FPI and less FDI. The intuition is that as the probability of an aggregate liquidity shock increases, agents know that they are more likely to need to sell the investment early, in which case, if they hold FDI, they will get a low price since buyers do not know whether they sell because of an individual liquidity need or because of adverse information on the productivity of the investment. As a result, the attractiveness of FDI decreases, and the ratio of FPI to FDI increases.

As mentioned above, the main advantage of this new specification is that it can be taken more easily to the data. Our main goal in this paper is indeed to test the prediction of the model. We use interest-rate hikes as indicators of an aggregate liquidity crisis. Using a Probit specification, we estimate the probability of an interest rate hike for each country and in every year of our sample. Then, we test the effect of this probability on the ratio between FPI and FDI generated by the source country. We find strong support for our model: a higher probability of a liquidity crisis, measured by the probability of episodes of negative purchase of external assets, has a significant positive effect on the ratio between FDI and FPI. We repeat this analysis using a real interest rate hike or a real exchange rate depreciation as an alternative indicator of a liquidity crisis, and get similar results.

Our paper is related to several other papers in the literature that study the determinants of FDI and FPI. These include Razin, Sadka and Yuen (1998), Albuquerque (2003), and others. Our paper is the first to study the effect of the probability of an aggregate liquidity crisis on the composition of foreign equity flows between FDI and FPI. Moreover, we are the first to study the determinants of FDI and FPI at the source country (other papers have focused on the host country).

The remainder of this paper is organized as follows: Section 2 reviews the model of idiosyncratic liquidity shocks by Goldstein and Razin (2006). In Section 3, we extend the model to introduce aggregate liquidity shocks. Section 4 describes the data and the econometric model used for the empirical analysis. In Section 5, we present the empirical results.

\section{Goldstein and Razin (2006): Idiosyncratic Liquidity Shocks}

We start by describing the model of Goldstein and Razin (2006), which studies a trade off between FDI and FPI based on the possibility of idiosyncratic liquidity shocks. 


\subsection{Efficiency of FDI}

A small economy is faced by a continuum $[0,1]$ of foreign investors. Each investor has an opportunity to invest in one investment project. Investment can occur in one of two forms: either a direct investment or a portfolio investment. A direct investor effectively acts like a manager, whereas in case of a portfolio investment, the project is managed by an "outsider". Investors are risk neutral, and thus choose the form of investment that maximizes ex-ante expected payoff.

There are three periods of time: 0,1 , and 2 . In period 0 , each investor decides whether to make a direct investment or a portfolio investment. In period 2, the project matures. The net cash flow from the project is denoted by $R(K, \varepsilon)$ :

$$
R(K, \varepsilon)=(1+\varepsilon) K-\frac{1}{2} A K^{2},
$$

where $\varepsilon$ is a random productivity factor that is independently realized for each project in period 1 , and $K$ is the level of capital input invested in the project in period 1, after the realization of $\varepsilon$. The productivity shock $\varepsilon$ is distributed between -1 and 1 with mean 0 . The cumulative distribution function is $G(\cdot)$, and the density function is $g(\cdot)=G^{\prime}(\cdot)$. The parameter $A$ reflects production costs.

In period 1, after the realization of the productivity shock, the manager of the project observes $\varepsilon$. Thus, if the investor owns the project as a direct investment, she observes $\varepsilon$, and chooses $K$, so as to maximize the net cash flow:

$$
K^{*}(\varepsilon)=\frac{1+\varepsilon}{A} .
$$

Then, the ex-ante expected net cash flow from a direct investment, if held until maturity, is:

$$
\frac{E\left((1+\varepsilon)^{2}\right)}{2 A} .
$$

In case of a portfolio investment, the owner is not the manager, and thus she does not observe $\varepsilon$. In this case, the manager follows earlier instructions as for the level of $K$. Following the logic described in Goldstein and Razin (2006), we assume that the ex-ante instruction is chosen by the owner so as to maximize the expected return absent any information on the realization of $\varepsilon$, and

is based on the ex-ante 0 mean. Thus, the manager will be instructed to choose $\bar{K}=K^{*}(0)=\frac{1}{A}$. Then, the ex-ante expected payoff from a portfolio investment, if held until maturity, is: 


$$
\frac{1}{2 A}
$$

Comparing (3) with (4), we see that if the project is held until maturity, it yields a higher payoff as a direct investment than as a portfolio investment. This reflects the efficiency that results from a hands-on management style in the case of a direct investment.

\subsection{Costs of FDI}

As in Goldstein and Razin (2006), there are costs to direct investments. We specify two types of costs. The first type, reflects the fixed initial cost that an FDI investor has to incur in order to acquire the expertise to manage the project directly. We denote this cost, which is exogenously given in the model, by $C$. The second type, which is derived endogenously in the model, results from the possibility of liquidity shocks occurring in period 1.

Specifically, in period 1 , before the value of $\varepsilon$ is observed, the owner of the project might get a liquidity shock. With the realization of a liquidity shock, the investor is forced to sell the project immediately. We denote by $\lambda$ the probability of liquidity shocks, and assume that there are two types of foreign investors: half of the investors face a liquidity need with probability $\lambda_{H}$, whereas the other half face a liquidity need with probability $\lambda_{L}$, where $1>\lambda_{H}>\frac{1}{2}>\lambda_{L}>0$, and $\lambda_{H}+\lambda_{L}=1$. Investors know their type ex ante, but this is their own private information.

In addition to liquidity-based sales, there is a possibility that an investor will liquidate a project in period 1 if she observes a low realization of $\varepsilon$. Because portfolio investors do not observe $\varepsilon$ in period 1, only direct investors sell their investment project at that time when a liquidity shock is absent. Then, using Bayes' Law, the price that buyers are willing to pay for a direct investment that is being sold in period 1 is:

$$
P_{1, D}=\frac{\left(1-\lambda_{D}\right) \int_{-1}^{\varepsilon_{D}} \frac{(1+\varepsilon)^{2}}{2 A} g(\varepsilon) d \varepsilon+\lambda_{D} \int_{-1}^{1} \frac{1+2 \varepsilon}{2 A} g(\varepsilon) d \varepsilon}{\left(1-\lambda_{D}\right) G\left(\underline{\varepsilon}_{D}\right)+\lambda_{D}} .
$$

Here, $\underline{\varepsilon}_{D}$ is the threshold level of $\varepsilon$, below which the direct investor is selling the project in absence of a liquidity shock; $\lambda_{D}$ is the probability, as perceived by the market, that an FDI investor gets a liquidity shock. In (5), it is assumed that if the project is sold due to a liquidity

shock, that is, before the initial owner observes $\varepsilon$, the value of $\varepsilon$ is not recorded in the firms before the sale. Therefore, the buyer does not know the value of $\varepsilon$. However, if the project is sold for low-profitability reasons, the owner will know the value of $\varepsilon$ after the sale. 
Of course, $\underline{\varepsilon}_{D}$ is determined in equilibrium. The initial owner sets the threshold level $\underline{\varepsilon}_{D}$, such that given $P_{1, D}$, when observing $\underline{\varepsilon}_{D}$, she is indifferent between selling and not selling the project. Thus:

$$
P_{1, D}=\frac{\left(1+\underline{\varepsilon}_{D}\right)^{2}}{2 A}
$$

Together, equations (5) and (6) determine $P_{1, D}$ and $\underline{\varepsilon}_{D}$ as functions of the market-perceived probability $\lambda_{D}$. We denote these functions as: $\underline{\varepsilon}_{D}\left(\lambda_{D}\right)$ and $P_{1, D}\left(\lambda_{D}\right)$.

The period-1 price of a portfolio investment is easier to determine. Essentially, when a portfolio investor sells the projects in period 1, everybody knows she does it because of a liquidity shock. Thus, the price she gets for the project is given by:

$$
P_{1, P}=\frac{1}{2 A}
$$

Comparing the price of FDI, which is determined by (5) and (6), with the price of FPI, which is determined by (7), we see that the resale price of a direct investment in period 1 is always lower than the resale price of a portfolio investment in that period. The intuition is that if a direct investor prematurely sells the investment project, the market price must reflect the possibility that the sale originates from inside information on low prospects of this investment project. This constitutes the second cost of FDI.

\subsection{The Decision between FDI and FPI}

Based on these prices, we can write down the ex-ante expected net cash flow from FDI and FPI. A direct investor with a probability $\lambda_{i}$ of a liquidity shock expects to get:

$$
\begin{aligned}
E V_{\text {Direct }}\left(\lambda_{i}, \lambda_{D}, A\right)= & \left(1-\lambda_{i}\right)\left[\begin{array}{c}
\int_{-1}^{\varepsilon_{D}\left(\lambda_{D}\right)} \frac{\left(1+\underline{\varepsilon}_{D}\left(\lambda_{D}\right)\right)^{2}}{2 A} g(\varepsilon) d \varepsilon \\
+\int_{\underline{\varepsilon}_{D}\left(\lambda_{D}\right)}^{1} \frac{(1+\varepsilon)^{2}}{2 A} g(\varepsilon) d \varepsilon
\end{array}\right] \\
& +\lambda_{i} \frac{\left(1+\underline{\varepsilon}_{D}\left(\lambda_{D}\right)\right)^{2}}{2 A}-C .
\end{aligned}
$$

Here, with probability $\lambda_{i}(i=H, L)$, the investor gets a liquidity shock, and sells the project in

period 1 for a price $P_{1, D}\left(\lambda_{D}\right)=\frac{\left(1+\underline{\varepsilon}_{D}\left(\lambda_{D}\right)\right)^{2}}{2 A}$. With probability $1-\lambda_{i}$, the investor does not get a liquidity shock. She sells the project if the realization of $\varepsilon$ is below $\underline{\varepsilon}_{D}\left(\lambda_{D}\right)$, but she does not sell it if the realization of $\varepsilon$ is above $\underline{\varepsilon}_{D}\left(\lambda_{D}\right)$. In addition, a direct investor has to incur a fixed cost of C. 
When the investor holds the investment as a portfolio investment, the ex-ante expected net cash flow is simply given by:

$$
E V_{\text {Portfolio }}(A)=\frac{1}{2 A} \text {. }
$$

This is because, no matter whether the investor gets a liquidity shock or not, her payoff is $\frac{1}{2 A}$.

We denote the difference between the expected value of FDI and the expected value of FPI by:

$$
\operatorname{Diff}\left(\lambda_{i}, \lambda_{D}, A\right) \equiv E V_{\text {Direct }}\left(\lambda_{i}, \lambda_{D}, A\right)-E V_{\text {Portfolio }}(A)
$$

Then, investor $i$ will choose FDI when $\operatorname{Diff}\left(\lambda_{i}, \lambda_{D}, A\right)>0$; will choose FPI when $\operatorname{Diff}\left(\lambda_{i}, \lambda_{D}, A\right)<$ 0; and will be indifferent between the two (that is, may choose either FDI or FPI) when Diff $\left(\lambda_{i}, \lambda_{D}, A\right)=$ 0 .

As is shown in Proposition 2 of Goldstein and Razin (2006), investor $i$ is more likely to choose FDI when the FDI cost $(C)$ is lower; the production cost $(A)$ is lower; the probability of getting a liquidity shock $\left(\lambda_{i}\right)$ is lower; and the market-perceived probability $\lambda_{D}$ of a liquidity shock for FDI investors is higher.

\subsection{FDI and FPI in Equilibrium}

To complete the description of equilibrium, it remains to specify how $\lambda_{D}$ is determined. Assuming that rational expectations hold in the market, $\lambda_{D}$ has to be consistent with the equilibrium choice of investors between FDI and FPI. thus, it is given by the following equation:

$$
\lambda_{D}=\frac{\lambda_{H} \lambda_{H, F D I}+\lambda_{L} \lambda_{L, F D I}}{\lambda_{H, F D I}+\lambda_{L, F D I}}
$$

where $\lambda_{H, F D I}$ is the proportion of $\lambda_{H}$ investors who choose FDI in equilibrium and $\lambda_{L, F D I}$ is the proportion of $\lambda_{L}$ investors who choose FDI in equilibrium.

Goldstein and Razin (2006) show that five cases can potentially be observed in equilibrium:

Case 1: All investors choose FDI.

Case 2: $\lambda_{L}$ investors choose FDI; $\lambda_{H}$ investors split between FDI and FPI.

Case 3: $\lambda_{L}$ investors choose FDI; $\lambda_{H}$ investors choose FPI.

Case 4: $\lambda_{L}$ investors split between FDI and FPI; $\lambda_{H}$ investors choose FPI.

Case 5: All investors choose FPI. 


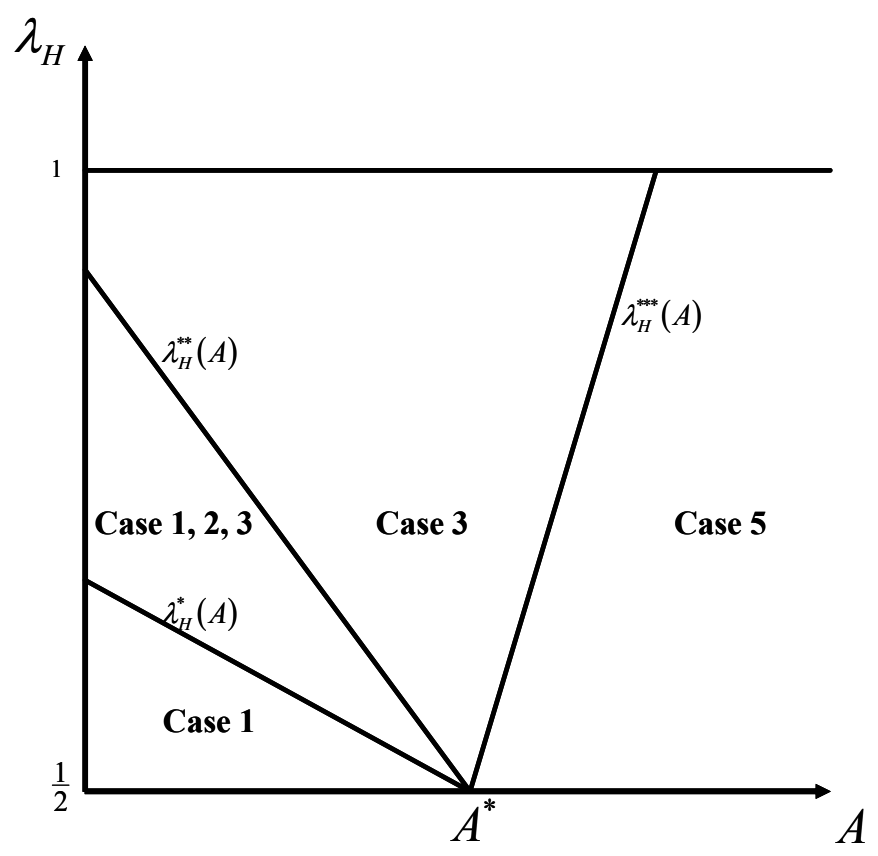

Figure 1: Equilibrium Outcomes

Proposition 3 in Goldstein and Razin (2006) shows that equilibrium outcomes depend on $\lambda_{H}$ and $A$ in a way that is depicted by Figure 1.

As we can see in the figure, the equilibrium patterns of investment are determined by the parameters $A$ and $\lambda_{H}$. Since $\lambda_{H}+\lambda_{L}=1$, the value of $\lambda_{H}$ also determines $\lambda_{L}$, and thus can be interpreted as a measure for the difference in liquidity needs between the two types of investors. In the figure we can see that there are four thresholds $-A^{*}, \lambda_{H}^{*}(A), \lambda_{H}^{* *}(A)$, and $\lambda_{H}^{* * *}(A)-$ that are important for the characterization of the equilibrium outcomes. These thresholds are defined in Goldstein and Razin (2006). Overall, we can see that as the production cost $A$ increases, we are more likely to observe FPI and less likely to observe FDI in equilibrium. As the difference in liquidity needs between the two types of investors increase, we are more likely to see a separating equilibrium, where different types of investors choose different forms of investment.

\section{Extension: Aggregate Liquidity Shock}

The model in Goldstein and Razin (2006) assumes that liquidity shocks to individual investors are completely idiosyncratic, i.e., there is no correlation between the realization of a liquidity shock for one investor and that for other investors. A more realistic assumption is that liquidity shocks to 
individual investors are triggered by some aggregate liquidity shock.

Suppose now that an aggregate liquidity shock occurs in period 1 with probability $q$. Once it occurs, it becomes common knowledge. Conditional on the realization of the aggregate liquidity shock, individual investors may be subject to a need to sell their investment at period 1 with probabilities as in the previous section. That is, if a liquidity shock occurs (with probability $q$ ) then half of the investors need to sell in period 1 with probability $\lambda_{H}$ and half with probability $\lambda_{L}$. Conditional on the realization of an aggregate liquidity shock, the realizations of individual liquidity needs are independent of each other. With probability $(1-q)$, an aggregate liquidity shock does not occur, and then individual investors never have a liquidity need that forces them to sell at period 1.

This specification of the model is admittedly simple. The idea that we are trying to capture with this specification is that individual investors are forced to sell their investments early at times when there are aggregate liquidity problems. In those times, some individual investors have deeper pockets than others, and thus are less exposed to the liquidity issues. Thus, once an aggregate liquidity shock occurs, $\lambda_{L}$ investors, who have deeper pockets, are less likely to need to sell than $\lambda_{H}$ investors.

The analysis of the model under the new extension is simple given the analysis of the model in the previous section. If an aggregate liquidity shock does not occur, then it is known that no investor needs to sell in period 1 due to liquidity needs. This implies that the only reason to sell at that time is adverse information on the profitability of the project. As a result, the market breaks down due to the well-known lemons problem (see Akerlof (1970)). Thus, when an aggregate liquidity shock does not occur, no investor sells her investment at period 1 . Investors wait till the maturity of the investment, and get $\frac{E\left((1+\varepsilon)^{2}\right)}{2 A}$ in case they hold a FDI (see (3)) and $\frac{1}{2 A}$ in case they hold a FPI (see (4)). On the other hand, if a liquidity shock does happen, the expected payoffs from FDI and FPI are exactly the same as in the previous section; see (8) for FDI and (9) for FPI. Essentially, the model in the previous section corresponds to the case of $q=1$.

Using these arguments, we can write the ex-ante expected net cash flow from FDI in the new 
model as (we use the superscript Ext to denote expected values in the extended model:

$$
\begin{aligned}
E V_{\text {Direct }}^{\text {Ext }}\left(\lambda_{i}, \lambda_{D}, A, q\right)= & q \int_{-1}^{1} \frac{(1+\varepsilon)^{2}}{2 A} g(\varepsilon) d \varepsilon \\
& +(1-q)\left[\begin{array}{c}
\left.\left(1-\lambda_{i}\right)\left[\begin{array}{c}
\int_{\underline{\varepsilon}_{D}}\left(\lambda_{D}\right) \\
-1 \\
+\int_{\underline{\varepsilon}_{D}\left(\lambda_{D}\right)}^{1} \frac{\left(1+\underline{\varepsilon}_{D}\left(\lambda_{D}\right)\right)^{2}}{2 A} g(\varepsilon) d \varepsilon \\
2 A
\end{array}\right) d(\varepsilon) d \varepsilon\right]-C . \\
+\lambda_{i} \frac{\left(1+\underline{\varepsilon}_{D}\left(\lambda_{D}\right)\right)^{2}}{2 A}
\end{array}\right]-.
\end{aligned}
$$

The ex-ante expected net cash flow from FPI in the new model is as before:

$$
E V_{\text {Portfolio }}^{\text {Ext }}(A)=\frac{1}{2 A} \text {. }
$$

Then, the difference between the expected value of FDI and the expected value of FPI is:

$$
\operatorname{Diff}{ }^{E x t}\left(\lambda_{i}, \lambda_{D}, A, q\right) \equiv E V_{\text {Direct }}\left(\lambda_{i}, \lambda_{D}, A, q\right)-E V_{\text {Portfolio }}(A)
$$

As before, investor $i$ will choose FDI when $\operatorname{Diff}\left(\lambda_{i}, \lambda_{D}, A, q\right)>0$; will choose FPI when $\operatorname{Diff}\left(\lambda_{i}, \lambda_{D}, A, q\right)<$ 0; and will be indifferent between the two (that is, may choose either FDI or FPI) when Diff $\left(\lambda_{i}, \lambda_{D}, A, q\right)=$ 0 .

Our main goal in introducing the aggregate liquidity shock is to be able to generate a testable empirical prediction on the relation between liquidity variables and the choice of investors between FDI and FPI. In the original model by Goldstein and Razin (2006), the probabilities of idiosyncratic liquidity shocks, $\lambda_{H}$ and $\lambda_{L}$, affected the equilibrium allocation between FDI and FPI. The problem, however, is that idiosyncratic liquidity shocks are not observable to econometricians. The big advantage of the current model is that $\lambda_{H}$ and $\lambda_{L}$ are now linked to $q$ - the probability of an aggregate liquidity shock, which is observable. Thus, our main interest is to derive a prediction on the effect that $q$ has on the ratio of FPI to FDI and then to test it.

Repeating the analysis in Proposition 3 of Goldstein and Razin (2006) for the extended model, one can see that the equilibrium outcomes still depend on the thresholds $A^{*}, \lambda_{H}^{*}(A), \lambda_{H}^{* *}(A)$, and $\lambda_{H}^{* * *}(A)$. These thresholds now depend on $q$. In particular, $A^{*}, \lambda_{H}^{*}(A)$, and $\lambda_{H}^{* *}(A)$ are decreasing in $q$, while $\lambda_{H}^{* * *}(A)$ is increasing in $q$. This implies that as the probability of an aggregate liquidity shock $q$ increases, there will be more FPI and less FDI in equilibrium. Thus, the ratio of FPI to FDI will increase. The intuition is that as the probability of an aggregate liquidity shock increases, agents know that they are more likely to need to sell the investment early, in which case they will get a low price since buyers do not know whether they sell because of an individual liquidity 
need or because of adverse information on the productivity of the investment. As a result, the attractiveness of FDI decreases. Note that there is a delicate point about this result, which comes from the fact that $q$ does not have an unambiguous effect on the function Diff $f^{E x t}$. The effect depends on the relation between $\lambda_{i}$ and $\lambda_{D}$. It is the equilibrium conditions that determine the thresholds $A^{*}, \lambda_{H}^{*}(A), \lambda_{H}^{* *}(A)$, and $\lambda_{H}^{* * *}(A)$ that guarantee that the equilibrium effect of $q$ on the frequency of FPI relative to FDI is unambiguously positive.

In sum, our prediction from the theoretical model is that countries that have a high probability of liquidity crisis will be the source of more FPI and less FDI. We now turn to test this prediction.

\section{Empirical Analysis}

\subsection{Data}

In this paper, we use the recently available data on a country's external assets and liabilities, as compiled by Lane and Milesi-Ferretti (2006). Lane and Milesi-Ferretti (2006) assemble a comprehensive dataset on the foreign assets and liabilities of 140 developed and developing countries for the period 1970-2004. They distinguish four types of international assets: foreign direct investment, portfolio equity investment, official reserves, and external debt. The convention for distinguishing between portfolio and direct investment is to see whether the ownership of shares of companies is above or below a ten percent threshold. If it is above the threshold, then it is classified as direct investment. ${ }^{1}$

For most countries, Lane and Milesi-Ferretti (2006) use as a benchmark the official International Investment Position (IIP) estimates. However, only very few countries have consistently reported their IIP over the period 1970-2004, with the majority of countries starting to report in the early 1990s, following the methodology described in the IMF Balance of Payments Manual, fifth edition, 1993. For earlier years, they then work backward with data on capital flows, together with calculations for capital gains and losses, to generate estimates for stock positions. In their estimation, due to cross-country variation in the reliability of the data, they also employ a range of valuation

\footnotetext{
${ }^{1}$ There is the problem of "borderline" cases where it is difficult to classify an investment as FDI or FPI. In countries where FPI is liberalized, a portfolio investor might buy more than 10 per cent of the shares of companies without having a "lasting interest" to control the companies. And yet that investor's investment can be classified as FDI. Using the control interest as a dividing line, there are circumstances where FDI can turn into FPI through the dilution of ownership and loss of control. Conversely, FPI can be transformed into FDI, if the investor decides to have a management interest in the companies whose assets it had earlier purchased as FPI.
} 
techniques to obtain the most appropriate series for each country. Particularly, they use the same valuation adjustment for FPI and FDI. In our following estimation, we use the data from 1985 to 2004 as our benchmark case.

Table 1 lists the countries covered in the sample from 1985 to 2004, as a source for FPI and FDI. From this table, we can see that developed countries have more observations on average than developing economies do, due to the fact that developed countries engage in more foreign investment than their developing counterparts. Table 1 also shows that developed countries tend to have higher ratio of FPI/FDI, which may reflect factors other than liquidity. In the following estimations, we will control for some standard determinants of FPI/FDI, as well as for unobservable country fixed effects. $^{2}$

\subsection{Econometric Model}

We investigate the effect of a country-level liquidity shock on the FPI/FDI ratio for source countries. The latter variable is the dependent variable in the following reduced form equation:

$$
\ln (F P I / F D I)_{i t}=\alpha X_{i t}+\beta \operatorname{Pr}_{i, t}\left(\text { Liquidity Shock }_{i, t+1}\right)+\gamma Y \text { ear } t+u_{i}+\varepsilon_{i t}
$$

for source country i at time t. $u_{i}$ stands for country fixed effect, while $\varepsilon_{i t}$ follows an i.i.d normal distribution. The vector $X_{i t}$ includes standard explanatory variables as follows. First, we put two variables - the log of the population and the log of GDP per capita (measured in constant US dollars) - to capture market size and the level of economic development. Note that GDP per capita may also be a proxy for some production cost parameter (the parameter $A$ in our model). Another variable, which is included in the vector, is the log of stock market capitalization over GDP. This captures how advanced the country's stock market is. ${ }^{3}$ A more developed stock market has more established professional asset management (mutual funds and hedge funds, for instance), which could help domestic investors to enter international stock markets and therefore increase FPI outflow. We also include a variable indicating trade openness. This is measured as the log of the sum of a country's imports and exports over its GDP.

\footnotetext{
${ }^{2}$ In principle, there could be a two-stage decision process as follows. In stage 1, a potential investor has to decide whether to engage in foreign investment. In stage 2, in what form to do it (FDI or FPI). Some missing observations may indicate situations where these countries did not cross the threshold for foreign investment, hence a Heckman selection model could be desirable.

${ }^{3}$ There might be an endogeneity issue regarding stock market capitalization, which will be dealt with later.
} 
The crux of our theory is that a higher probability of an aggregate liquidity shock (the variable q) increases the share of FPI, relative to FDI. Therefore we include in equation (15) a variable, $\operatorname{Pr}_{i, t}\left(\right.$ Liquidity $\left.S h o c k_{i, t+1}\right)$, to proxy this probability in period $\mathrm{t}+1$, as perceived in period t. ${ }^{4} \mathrm{We}$ emphasize that we look at the probability of such a hike to occur irrespective of whether such a hike actually occurs. ${ }^{5}$

We define the liquidity crisis as episodes of negative purchase of external assets. The flow data on external assets is from the International Financial Statistics's Balance of Payments, where assets include foreign direct investment, foreign portfolio investment, other investments and foreign reserves. We thus define the liquidity crisis episodes as sales of external assets, which has a frequency of $13 \%$ in our sample of 140 countries from 1985 to 2004 . Note that the Balance of Payments data do not control for valuation effect. Therefore, they could capture the notion of the quantity of investment liquidations in our model. Table 2 lists the country and year when there is a negative purchase of external assets, and the sample average of FDI and FPI stocks relative to GDP for these countries. Note that besides developing countries, some developed economies, such as Denmark, Japan, New Zealand and Spain, also experienced liquidity crises in the sample period.

\footnotetext{
${ }^{4}$ In recent literature, financial and liquidity crises are triggered not only by fundamental shocks, but also by the degree to which market expectations about these fundamentals are coordinated (Morris and Shin, 2000). In the absence of common knowledge, an individual market participant receives not only an independent and noisy signal about the fundamentals but also must have some uncertainty about the other market participants' expectations. Morris and Shin (2000) show how the market participants' knowledge about the statistical distributions of signals and market fundamentals helps to coordinate the behaviour of market participants. The coordination of expectations induces a unique equilibrium in such a set up, in which there exists a threshold level of the fundamental. As a consequence, the equilibrium macroeconomic performance can be specified as a one-to-one function of a fundamental ex-ante probability of the financial crisis, derived from the probability distribution of the fundamentals correlated with the macroeconomic performance. This gives a theoretical underpinning for the econometric model applied here. The inclusion of the liquidity shock probability is inspired by Razin and Rubinstein (2006), where they stress the importance of including the probability of currency crisis in estimating the relationship between exchange rate regime and economic growth.

${ }^{5}$ An econometrically equivalent way is to use the dummy of realized crises at time $t+1$, instrumented by $\operatorname{Pr}_{i, t}\left(\right.$ Liquidity Shock $\left._{i, t+1}\right)$. But economically, at time $t$, investors can not observe whether there will be a crisis or not at time $t+1$. That is, the actual occurrence of the crisis at $t+1$ is not an information investors can use at $t$. What investors can use at $t$ is only the estimated probability of crisis.
}

Also, if $\boldsymbol{\square}_{i}$ is the same for all source countries, as assumed in our model, then the estimated $\beta$ stands for the average of all countries in the sample (including, say, the U.S. which never experienced crisis). But if $\mathbf{Q}_{i}$ varies across source countries, then the estimated $\beta$ stand for the average of those countries which at some point experienced a shock, as illustrated in Angrist and Imbens (1994). 
To estimate the probability of liquidity crises, we apply the following Probit model:

$$
I_{i, t}\left(\text { Liquidity } \text { Crisis }_{i, t+1}\right)=\left\{\begin{array}{l}
1 \text { if } y_{i, t+1}^{*}>0 \\
0 \text { if } y_{i, t+1}^{*} \leq 0
\end{array},\right.
$$

where $y_{i, t+1}^{*}$, a latent variable, is a function of the following independent variables:

$$
y_{i, t+1}^{*}=Z_{i t}^{\prime} \lambda+\eta_{i, t+1}
$$

where $\eta_{i, t+1}$ have a standard normal distribution. The vector $Z_{i t}^{\prime}$ includes the log of population, the log of GDP per capita, the real interest rate at the U.S., and Standard and Poor's shortterm sovereign rating ${ }^{6}$. When the sovereign rating is poor, government, banks and non-financial firms find it expensive to borrow abroad and therefore compete for domestic resources, creating a upward pressure on interest rates.

Except for the first two variables, all other variables in equation (16) are not in equation (15), which satisfies the exclusion restriction. These other variables are standard in the empirical literature on liquidity crises. Furthermore, they are excluded from equation (15), as our theory indeed does not assign them a direct role in determining the ratio of FPI to FDI. Note that equation (15) can be identified even with a common set of explanatory variables because it is a linear form, whereas the predicted $\operatorname{Pr}(\text { Liquidity Shock })_{i, t+1}$ is a non-linear combination of these common explanatory variables $Z_{i t}^{\prime}$. However, functional form identification tends to be weak and unstable, which is why we include in equation (16) the variables that are likely to affect the probability of liquidity crisis but are unlikely to affect FPI/FDI. Thus, we identify this system both by differential functional forms and by exclusion restrictions.

\section{$5 \quad$ Empirical Results}

\subsection{Probit}

We use pooled specification to predict the liquidity crisis, in that fixed-effect Probit regressions are not consistent estimations due to the incidental parameters problem (p697, Greene 2002). ${ }^{7}$ Table

\footnotetext{
${ }^{6}$ We use numeric representation of the rating, with smaller number corresponding to higher risk, i.e. worse rating.

${ }^{7}$ The estimator relies on $T_{i}$ increasing for the constant terms (fixed effects) to be consistent. But in this model, $T_{i}$ is both small and fixed. Hence, the estimators of the constant terms are not consistent. That is, they do not converge at all. The estimator of $\beta$ is a function of the estimators of the fixed effects, which means taht the estimation of $\beta$ is not consistent either. Note that one cannot solve the incidental parameter problem by dropping countries which never experienced a crisis.
} 
3 presents the Probit estimation for all countries from 1985 to 2004, subject to data availability. As expected, larger economic size and higher development level reduces the occurence of liquidity crises. Moreover, higher U.S. interest rate increases the probability of liquidity crisis, while higher sovereign rating lowers it. Since both sovereign rating and U.S. interest rate are significant in the Probit estimation, we can then identify the effect of liquidity shock on FPI/FDI through functional form as well as exclusion restrictions. According to Table 3, the predicted probability of liquidity crises in the sample lies between 0 and 0.32 , with a mean of $0.07 .^{8}$

\subsection{Ratio of FPI to FDI}

With the predicted probability of liquidity crises, we can now estimate equation (15). We take the log of the FPI/FDI ratio as our dependent variable, to reduce the impact of extreme values. The results are reported in Table 4 . Case 1 reports the results with country and time fixed effects. As our theory predicts, a higher probability of an aggregated liquidity shock significantly increases the share of FPI, relative to FDI. Moreover, stock market capitalization/GDP increases FPI, while trade openness complements FDI.

One might be concerned that lagged FPI/FDI could also affect current FPI/FDI ${ }^{9}$ Hence we estimate, alternatively, the following dynamic panel regression.

$\ln (F P I / F D I)_{i t}=\phi \ln (F P I / F D I)_{i, t-1}+\alpha X_{i t}+\beta \operatorname{Pr}_{i, t}\left(\right.$ Liquidity Shock $\left._{i, t+1}\right)+\gamma$ Year $_{t}+u_{i}+\varepsilon_{i t}$

There is a complication in estimating equation (17). That is, if $\varepsilon_{i t}$ is not i.i.d, but instead seriallycorrelated, then the explanatory variable $\ln (F P I / F D I)_{i, t-1}$ will be correlated with $\varepsilon_{i t}$, and thus create an endogeneity problem. Hence, we use the Arellano-Bond dynamic GMM approach to estimate equation (17), which corrects this endogeneity problem.

Case 2 in Table 4 reports the dynamic panel estimation. Dynamic estimation reduces the sample size, but reassuringly, results from fixed effect estimation still carry through. We find that stock market capitalization and trade openness keep their signs and significance level. Moreover, higher

\footnotetext{
${ }^{8}$ The R-square of the Probit estimation is 0.13. Arguably, it is not large. We use Probit to test the hypothesis that the probability of crises matters, but we are not too concerned about the degree of fitness of the Probit, as long as it is an unbiased estimate of the probability.

${ }^{9}$ Arguably, in our model, investors can rebalance their portfolio of assets every period. thus, the stocks of external assets rather than the flows are consistent with the model. But the choice of the stock at time $t$ may need to use the information set conveyed in the stock at time $t-1$. Therefore, empirically, we may need to allow for the agged dependent variable in the equation to control for the dynamics of the information set.
} 
probability of aggregated liquidity shocks increases FPI relative to FDI. One percentage increase of the probability will increase the ratio of FPI/FDI by $3.9 \%$. ${ }^{10}$

We also find that the one-year lagged FPI/FDI ratio is associated with current FPI/FDI ratio. The coefficient of the lagged FPI/FDI is around 0.47, which suggests that there is no panel unit root process for FPI/FDI. Additional Arellano-Bond tests strongly reject the hypothesis of no first-order autocorrelation in residuals, but fail to reject the hypothesis of no second-order autocorrelation. Hence, the estimations in Table 4 are valid and provide strong empirical support for our theory.

\subsection{Levels of FDI and FPI}

It would be of interest to see how each component of foreign investment moves with the likelihood of liquidity crisis. Hence, in Table 5, we look at how FDI and FPI respond respectively to the probability of liquidity crisis. We apply the dynamic panel estimation to separate the level equation of FDI and FPI. We can see that both the FDI and the FPI drop as the likelihood of liquidation rises. However, there is a significantly larger drop of FDI, consistent with our early result in Table 4 where we look at the ratio. ${ }^{11}$

\subsection{Capital Market Transparency in Source Country}

Now we introduce an opacity index that is inversely related to capital market transparency. The Opacity Index was constructed in 2004 by Pricewaterhouse-Coopers. It covers corruption (COR), efficacy of the legal system (LEG), deleterious economic policy (ENF), inadequate accounting and governance practices (ACC), and detrimental regulatory structures (REG) ${ }^{12}$

We select the accounting opacity index from the overall opacity index. The accounting index is based on the following survey questions: Have exchanges established disclosure requirements?Are large shareholders required to disclose ownership? Are annual reports available to the public on demand? Are public corporations' financial statements required to be reviewed by an external auditor? Are the country's accounting standards on disclosure in accordance with International Accounting Standards? And must firms account for financial assets at fair market value? Hence,

\footnotetext{
${ }^{10}$ The median of the dependent variable (i.e, the $\log$ of FDI/FPI) is -0.64 , with the $25 \%$ quartile cutoff at -1.63 and the $75 \%$ quartile cutoff at -0.06 . Hence, if the probability of the crisis rises by $20 \%$, then the dependent variable will move from the median into the $25 \%$ quartile, ceteris paribus.

${ }^{11}$ The coefficients suggest that a $1 \%$ increase in the probability of the crisis will reduce FPI by $1.53 \%$ and FDI by $2.33 \%$. Note that the average of the probability is $7 \%$.

${ }^{12}$ http://www.opacityindex.com/opacity_index.pdf
} 
the accounting index seems to capture cross-country differences in capital market transparency. Table 6 lists the opacity index for accounting, as well as the overall opacity index. The higher the opacity index, presumably the higher the degree of asymmetric info in the country.

We estimate the following equation

$$
\begin{array}{r}
\ln (F P I / F D I)_{i t}=\phi \ln (F P I / F D I)_{i, t-1}+\alpha X_{i t}+\beta_{0} \operatorname{Pr}_{i, t}\left(\text { Liquidity Shock }_{i, t+1}\right)+ \\
\beta_{1} \text { Opacity }_{i} * \operatorname{Pr}_{i, t}\left(\text { Liquidity Shock } \text { Sh,t+1 }_{i}\right)+\gamma \text { Year } \\
+
\end{array}
$$

According to our theoretical model, the higher is the opacity in the source country, the higher is the adverse selection in the capital market. Hence higher opacity accelerates the effect of the probability of liquidity shock on FPI/FDI. Therefore, we expect to see a positive value of $\beta_{1}{ }^{13}$

The results are presented in Table 7 . Case 1 looks at the pure fixed effect model, while Case 2 examines the dynamic panel model. Consistent with our expectation, in both cases, higher opacity increases the effect of predicted liquidity crisis. Note that as the accounting opacity index ranges from 17 to 63 , the net effect of the predicted liquidity crisis is negative in half of the source countries, and positive in the other half. ${ }^{14}$

\section{Robustness Checks}

\subsection{Probit Estimations}

As a robustness check, we add dummies for semi decades into our Probit estimation for the liquidity crisis. This helps capture unobservable global trends that may affect the crisis. The R-square of the Probit increases from 0.12 to 0.15 . We find that explanatory variables maintain their signs and significances in the Probit model. Moreover, there is evidence that the semi-decade period from 2000 to 2004 saw much fewer liquidity crises than previous semi-decades. We then apply this newly estimated probability to the pure fixed effect FPI/FDI model as well as the dynamic one. We find that the estimated probability still has significant explanatory powers in both models. For example, in the dynamic model, it has an estimated coefficient of 3.15 and a p-value of $0.000 .{ }^{15}$

\footnotetext{
${ }^{13}$ We do not include the Opacity index itself as an explanatory variable, as it is not time-varying and is therefore imbedded in country fixed effects.

${ }^{14}$ Note that our sample size in Table 7 is around $70 \%$ of that in Table 4, as some source countries are not covered by the Opacity Index.

${ }^{15}$ We cannot include in the Probit model time effects for every year, which would then perfectly predict U.S. annual interest rate.
} 
Some might be concerned with the potential endogeneity of sovereign rating. Hence, we use the one-year lagged rating instead of the current rating, and get results similar to those in Tables 3 and 4.

\subsection{Non-linearity}

It would be of interest to examine whether there is nonlinearity in the effect of the predicted probability. Hence, we add the square of the predicted probability as an additional explanatory variable for the FPI/FDI ratio. The results for the dynamic model are reported in Table 8. We can see that the quadratic term is significant at $6 \%$ level, while the linear term is not significant (Case 1). Thus, we drop the linear term (Case 2). The quadratic term now becomes significant at the $1 \%$ level. Based on the estimation in Case 2, the margin effect of the predict probability is $1.65(=2 * 13.80 * 0.06)$ on average, where 0.06 is the mean of the predicted probability. Note that this marginal effect is less than half of the estimate in Table 4 (i.e, 3.93). Hence, the seemly over large effect of the predicted probability in Table 4 is partially driven by the nonlinearity. After we control for the nonlinearity, we get a more sensible effect.

Earlier, we use stock market capitalization over GDP as a control variable for the development level of stock market. One may argue that stock market capitalization over GDP can be affected by stock return and might be endogenous. Hence, as a robustness check, we use an alternative measure of the depth of stock market, i.e, the total value of shares traded over GDP. This variable also comes from the World Development Indicator, and we use its log value to reduce the impacts from extreme values. Again, we find that the higher the stock trade/GDP is, the higher the ratio of FPI to FDI. More importantly, our key variable, the predicted probability of liquidity crises is still significantly different from zero at the $5 \%$ level. ${ }^{16}$ Alternatively, if we just drop stock market development from the equation, we still get similar results for the effect of the predicted probability.

As a further sensitivity check, we use the one-year lags of FPI stock (log) and FDI stock (log) as explanatory variables, rather than the lag of the FPI/FDI ratio. We find that the lag of FPI has a coefficient of 0.60 , while the lag of FDI has a coefficient of $-0.55 .{ }^{17}$ More importantly, the probability of crises still has a significant impact, with a coefficient of 2.40 and a p-value of 0.01 .

\footnotetext{
${ }^{16}$ The estimated coefficient is 2.47 , with a p-value of 0.45 .

${ }^{17}$ This suggests that if the lag of FPI/FDI is used, it would has a coefficient between 0.55 and 0.60 , close to 0.47 in Table 4.
} 


\subsection{Probability or Realization of Future Crises}

We include the actual occurrence of liquidity crisis at period $t+1$, instead of the probability of the liquidity crisis at period $t+1$. We find that the actual crisis has a coefficient of 0.15 , smaller than that for the predicted probability in Table 4 (i.e, 3.93), and is different from zero only at the $10 \%$ level. This suggests that the predicted probability of the crisis, rather than the actual occurrence of the crisis, is the driving force behind the FPI/FDI choice.

\subsection{Alternative Indicator of a Liquidity Crisis}

As an alternative measurement, we define liquidity crisis as an event of a big increase in the real interest rate of over 4 percentage points in one year, with the data on interest rates coming from the World Bank's World Development Indicators. According to this definition, $15 \%$ of the sample experienced liquidity crises. The correlation between the interest rate hike dummy and the asset liquation dummy is around 0.10. Table 9 presents a list of countries for which our liquidity crisis indicator is equal to 1 over the period from 1985 to 2004 .

Again, we first apply Probit model to predict the one-year ahead liquidity crisis. We use the same explanatory variables as in Table 3: country population size, GDP per capita, U.S. interest rate, and Standard and Poor's short-term sovereign rating. Table 10 reports the Probit estimation for 140 countries from 1985 to 2004 . We can see that higher U.S. interest rate significantly increases the likelihood of interest rate hike, while higher country rating reduces the likelihood.

Based on Table 10, we construct the probability of interest rate hikes, and then examine its impact on FPI/FDI for the period from 1985 to 2004. Results are reported in Table 11. Case 1 is for the pure fixed effect model. We see that the higher the probability of hike, the higher the ratio of FPI relative to FDI. Case 2 is for the dynamic panel model. We find that lagged FPI/FDI explains current FPI/FDI, trade openness decreases FPI/FDI, while stock market capitalization increases it. Our key variable, the probability of currency crisis, still explains the choice between FDI and FPI, consistent with our theory as well as earlier results in Table 4.

We also define a stricter measure where crisis is defined as an increase in the real interest rate of over $7 \%$ a year (10\% of the sample). Robustness checks suggest that the stricter definition strengthens our key results. 


\section{Conclusion}

In this paper, we examine how the liquidity shock guides international investors in choosing between FPI and FDI. According to Goldstein and Razin (2006), FDI investors control the management of the firms; whereas FPI investors delegate decisions to managers. Consequently, direct investors are more informed than portfolio investors about the prospect of projects. This information enables them to manage their projects more efficiently. However, if investors need to sell their investments before maturity because of liquidity shocks, the price they can get will be lower when buyers know that they have more information on investment projects. We extend the Goldstein and Razin (2006) model by making the assumption that liquidity shocks to individual investors are triggered by some aggregate liquidity shock. A key prediction then is that countries that have a high probability of an aggregate liquidity crisis will be the source of more FPI and less FDI.

To test this hypothesis, we therefore apply a dynamic panel model to examine the variation of FPI relative to FDI for 140 source countries from 1990 to 2004. We use episodes of negative purchase of external assets as a proxy for liquidity crises. Using a Probit specification, we estimate the probability of liquidity crises for each country and in every year of our sample. Then, we test the effect of this probability on the ratio between FPI and FDI generated by the source country. We find strong support for our model: a higher probability of a liquidity crisis, measured by the probability of episodes of negative purchase of external assets, has a significant positive effect on the ratio between FDI and FPI. Moreover, higher opacity in the source country accelerates the effect of the probability of liquidity shock on FPI/FDI. We repeat this analysis using real interest rate hike or real exchange rate depreciation as an alternative indicator of a liquidity crisis, and get similar results. Hence, liquidity shocks do have strong effects on the composition of foreign investment, as predicted by our model. 


\section{References}

[1] Akerlof, George. A. (1970), "The Market for Lemons: Quality Uncertainty and the Market Mechanism", Quarterly Journal of Economics, 84, 488-500.

[2] Albuquerque, Rui (2003), "The Composition of International Capital Flows: Risk-Sharing through Foreign Direct Investment", Journal of International Economics, 61(2), 353-383.

[3] Albuquerque, Rui, Norman Loayza and Luis Serven (2005), "World Market Integration through the Lens of Foreign Direct Investors", Journal of International Economics, 66, 267295.

[4] Angrist, Joshua, and Guido Imbens (1994), "Identification and Estimation of Local Average Treatment Effects", Econometrica, 62, 467-475.

[5] Goldstein, Itay and Assaf Razin (2006), "An information - based Tradeoff between Foreign Direct Investment and Foreign Portfolio investment", Journal of International Economics, forthcoming.

[6] Greene, William (2002), Econometric Analysis (5th edition), Prentice Hall.

[7] Lane, Philip and Gian Maria Milesi-Ferretti (2006), "The External Wealth of Nations Mark II: Revised and Extended Estimates of Foreign Assets and Liabilities, 1970-2004," IMF Working Papers 06/69.

[8] Razin, Assaf, Efraim Sadka, and Chi-Wa Yuen (1998), "A Pecking Order Theory of Capital Flows and International Tax Principles", Journal of International Economics, 44, 45-68.

[9] Razin, Assaf and Yona Rubinstein (2006), "Evaluation of currency regimes: the unique role of sudden stops," Economic Policy, 21, 119-152. 


\section{Appendix-Currency Crises}

We use the depreciation of real exchange rate as an alternative measurement of liquidity crisis. The depreciation shrinks the purchasing power of domestic currency and thus decreases the ability of domestic firms to invest abroad. We use the real exchange rate vs. U.S. dollar, instead of the trade-weighted real effective exchange rate. ${ }^{18}$ We define currency crisis as the depreciation of more than $15 \%$ a year, which is about $5 \%$ of the sample.

Again, we first apply Probit model to predict the one-year ahead currency crisis. Based on the literature on currency crisis, we use the following explanatory variables: country population size, GDP per capita, GDP growth rate, money stock, U.S. interest rate, trade openness, and foreign reserves over imports. We do not include Standard and Poor's country rating here, because it shrinks the sample size while having no explanatory power on currency crisis. Table A.1 reports the Probit estimation for 140 countries from 1970 to 2004 . We can see that higher GDP per capita, higher economic growth, higher reserves over imports and trade openness all contribute to the reduction of currency crises. U.S. interest rate, on the contrary, significantly increases the likelihood of currency crises. All these are intuitive and consistent with previous literature.

Based on Table A.1, we construct the probability of currency crisis, and then examine its impact on FPI/FDI for the period from 1990 to 2004. Results are reported in Table A.2 ${ }^{19}$ Case 1 is for the pure fixed effect model. We see that the higher the probability of currency crisis, the higher the ratio of FPI relative to FDI. Case 2 is for the dynamic panel model. Again, we can see that the past movement of FPI/FDI explains the current variation of FPI/FDI. Higher GDP per capita and trade openness decrease the share of FPI relative to FDI. Our key variable, the probability of currency crisis, still explains the choice between FDI and FPI, consistent with our theory as well as earlier results in Table 4.

Both case1 and 2 include year dummies to capture unobservable global factors as well as potential global trends. In both cases, there seems to be a trend of growing FPI relative to FDI, judging from point estimates. The inclusion of year dummies, however, could potentially bias down our estimation, because they also capture global liquidity shock caused by higher U.S. interest rate. Hence, we use a time trend variable instead of year fixed effects in the dynamic model (Case 3). We

\footnotetext{
${ }^{18}$ One can collect the data for the latter from the IMF's International Financial Statistics, but will miss quite a few countries such as Brazil and Thailand. That is why we use the real exchange rate vs. dollar.

${ }^{19}$ Table A.2 covers more countries than Table 4, in that we do not include S\&P's country rating as an predictor of currency crises.
} 
can see that there is indeed a significant time trend. Moreover, the coefficient of crisis probability now rises to 5.8. This confirms our argument that time fixed effects bias down the effect of currency crisis. 
Table 1: Ratio of FPI to FDI: Summary Statistics

\begin{tabular}{|c|c|c|c|c|c|}
\hline Country Name & Obs & Mean & Country Name & Obs & Mean \\
\hline United States & 15 & -0.56 & Cambodia & 8 & -0.09 \\
\hline United Kingdom & 15 & -0.14 & Taiwan Province of China & 15 & -1.14 \\
\hline Austria & 15 & -0.32 & Hong Kong S.A.R. of China & 15 & -1.37 \\
\hline Belgium & 15 & -0.37 & India & 15 & -0.67 \\
\hline Denmark & 15 & -0.69 & Indonesia & 4 & -4.51 \\
\hline France & 15 & -1.57 & Korea & 15 & -2.18 \\
\hline Germany & 15 & -0.28 & Malaysia & 15 & -2.27 \\
\hline Italy & 15 & -0.40 & Pakistan & 3 & -2.51 \\
\hline Luxembourg & 5 & -0.22 & Philippines & 15 & -0.17 \\
\hline Netherlands & 15 & -0.58 & Singapore & 15 & 0.05 \\
\hline Norway & 15 & -0.88 & Thailand & 14 & -3.66 \\
\hline Sweden & 15 & -1.11 & Algeria & 14 & -7.45 \\
\hline Switzerland & 15 & -0.10 & Botswana & 11 & -0.16 \\
\hline Canada & 15 & 0.05 & Congo, Republic of & 10 & 0.30 \\
\hline Japan & 15 & -0.52 & Benin & 9 & -3.63 \\
\hline Finland & 15 & -2.27 & Gabon & 7 & -2.98 \\
\hline Greece & 15 & -0.62 & Côte d'Ivoire & 14 & -1.07 \\
\hline Iceland & 14 & -0.24 & Kenya & 15 & -3.48 \\
\hline Ireland & 15 & 1.02 & Libya & 15 & 3.04 \\
\hline Malta & 11 & -1.39 & Mali & 8 & -3.66 \\
\hline Portugal & 15 & -0.50 & Mauritius & 6 & -1.38 \\
\hline Spain & 15 & -1.26 & Niger & 8 & -5.38 \\
\hline Turkey & 14 & 0.43 & Rwanda & 6 & -0.33 \\
\hline Australia & 15 & -0.64 & Senegal & 15 & -1.27 \\
\hline New Zealand & 15 & -0.72 & Namibia & 14 & 0.65 \\
\hline South Africa & 15 & -0.66 & Swaziland & 13 & -3.94 \\
\hline Argentina & 15 & 0.16 & Togo & 13 & -1.95 \\
\hline Brazil & 15 & -2.91 & Tunisia & 15 & 2.08 \\
\hline Chile & 15 & -0.22 & Burkina Faso & 5 & -2.04 \\
\hline Colombia & 15 & -0.91 & Armenia & 8 & -1.58 \\
\hline Costa Rica & 10 & -1.04 & Belarus & 8 & -1.13 \\
\hline Dominican Republic & 9 & -0.54 & Kazakhstan & 6 & -0.28 \\
\hline El Salvador & 4 & 0.58 & Bulgaria & 8 & -0.52 \\
\hline Mexico & 15 & -0.40 & Moldova & 11 & -3.99 \\
\hline Paraguay & 15 & -3.11 & Russia & 13 & -4.70 \\
\hline Peru & 15 & 0.73 & China,P.R.: Mainland & 15 & -2.94 \\
\hline Uruguay & 15 & -0.22 & Ukraine & 9 & -0.37 \\
\hline Venezuela, Rep. Bol. & 15 & -1.12 & Czech Republic & 12 & 0.33 \\
\hline Trinidad and Tobago & 10 & -2.32 & Slovak Republic & 12 & 1.22 \\
\hline Bahrain & 15 & 0.60 & Estonia & 11 & -2.00 \\
\hline Cyprus & 6 & 0.04 & Latvia & 11 & -1.20 \\
\hline Israel & 15 & -0.27 & Hungary & 14 & -1.88 \\
\hline Jordan & 8 & 1.79 & Lithuania & 12 & -1.47 \\
\hline Lebanon & 4 & -0.06 & Croatia & 8 & -3.11 \\
\hline Saudi Arabia & 13 & -0.89 & Slovenia & 11 & -2.79 \\
\hline United Arab Emirates & 15 & 5.66 & Macedonia & 7 & 2.01 \\
\hline Egypt & 8 & -0.16 & Poland & 7 & -1.97 \\
\hline Bangladesh & 5 & -3.17 & Romania & 7 & -2.86 \\
\hline
\end{tabular}




\section{Table 2: Episodes of Sales of External Assets, and Levels of FDI FPI}

\begin{tabular}{|c|c|}
\hline Algeria & 1987,1986 \\
\hline Argentina & $2001,1989,1987,1986$ \\
\hline Bahrain & $2002,2001,1995,1993,1991,1990,1987$ \\
\hline Belarus & $2003,1998,1997$ \\
\hline Brazil & $1999,1997,1986$ \\
\hline Bulgaria & 1996 \\
\hline Chile & $1993,1987,1986$ \\
\hline Colombia & $2002,1998,1995$ \\
\hline Costa Rica & 2002,1998 \\
\hline Croatia & 1998, \\
\hline Denmark & 1994 \\
\hline Dominican Republic & 2000,1996 \\
\hline Egypt & 1999,1998, \\
\hline Greece & 2001,2000,1997,1995,1992,1989, \\
\hline Hong Kong S.A.R. of China & 2001,1998 \\
\hline Hungary & 1994, \\
\hline Iceland & 1994 \\
\hline India & $1995,1990,1989,1988,1987,1986$, \\
\hline Indonesia & 2001 \\
\hline Israel & 1988,1987 \\
\hline Japan & 1999 \\
\hline Kazakhstan & 1998 \\
\hline Kenya & 1997,1996,1995,1994,1990,1987, \\
\hline Latvia & 1995 \\
\hline Lebanon & $2004,2003,2002$ \\
\hline Libya & 1993,1991,1988,1987, \\
\hline Lithuania & 1999 \\
\hline Macedonia & 2002 \\
\hline Malaysia & $1996,1995,1994$, \\
\hline Malta & 2001,1994 \\
\hline Mauritius & 1998 \\
\hline Mexico & $2002,2000,1994,1992,1988$, \\
\hline Moldova & 1998, \\
\hline New Zealand & 1997,1992,1991,1988, \\
\hline Niger & $2002,1998,1997,1996$, \\
\hline Pakistan & 2004 \\
\hline Paraguay & 2002,2001,1997,1992,1988,1987,1986, \\
\hline Peru & $2000,1999,1998,1990,1987,1986$ \\
\hline Philippines & $2001,2000,1997,1990,1987$, \\
\hline Poland & 1996, \\
\hline Romania & $1999,1998,1995$ \\
\hline Rwanda & 2003 \\
\hline Saudi Arabia & 1998,1996,1995,1994,1993,1992, \\
\hline Senegal & 1993,1990,1987,1986, \\
\hline Slovak Republic & 1999,1998, \\
\hline Spain & 1994 \\
\hline Swaziland & 2003 \\
\hline Thailand & 1997, \\
\hline Togo & 2001,1998,1993,1992,1987,1986, \\
\hline Turkey & 2001,1994, \\
\hline Ukraine & 1998 \\
\hline Uruguay & 2002 \\
\hline Venezuela, Rep. Bol. & 1995,1992,1988,1987,1986, \\
\hline
\end{tabular}


Table 3: Probit Estimation of the Likelihood of Liquidity Crises

\begin{tabular}{lcc}
\hline & Coef. & Std. Err. \\
\hline Population $(\log )$ & $-0.10^{*}$ & 0.05 \\
\hline GDP per capita $(\log )$ & -0.18 & 0.10 \\
\hline U.S. real interest rate & $0.11^{*}$ & 0.04 \\
\hline Sovereign rating & $-0.18^{*}$ & 0.06 \\
\hline Constant & 2.03 & 1.24 \\
\hline R-square & 0.13 & \\
\hline Observations & 776 & \\
\hline
\end{tabular}

Note: Table 3 estimates the probability of liquidity crises for 140 countries over the period 1985-2004. The dependent variable is the liquidation of source country's foreign asset. Sovereign rating is from Standard and Poor's, while all other variables are from the WDI. A pooled Probit regression is estimated. * indicates significance at $5 \%$. 


\section{Table 4: Determinants of the Ratio of FPI over FDI}

\begin{tabular}{lcccc}
\hline & \multicolumn{2}{c}{ Case 1 } & \multicolumn{2}{c}{ Case 2 } \\
\hline & Coef & St. err. & Coef & St. err. \\
\hline Log of FPI/FDI (one-period lag) & & & $0.47^{*}$ & 0.04 \\
\hline Population (log) & $-3.02^{*}$ & 0.76 & $-2.73^{*}$ & 1.22 \\
\hline GDP per capita (log) & 0.46 & 0.34 & 0.65 & 0.37 \\
\hline Stock market capitalization & $0.36^{*}$ & 0.06 & $0.22^{*}$ & 0.06 \\
\hline Trade openness (log) & -0.31 & 0.25 & $-0.70^{*}$ & 0.23 \\
\hline Probability of liquidity crisis & $4.67^{*}$ & 1.23 & $3.93^{*}$ & 1.19 \\
\hline Observations & 697 & & 603 & \\
\hline
\end{tabular}

Note: The dependent variable is the log of FPI stock over FDI stock, for 140 source countries over the period from 1985 to 2004 . The estimated probability of liquidity crisis is based on the estimates from Table 3. All other explanatory variables are from the WDI. Case 1 is the panel estimation with country and year fixed effects. Case 2 adds a one-year-lagged dependent variable as an explanatory variable, and estimates a dynamic panel model. * indicates significance at $5 \%$. 


\section{Table 5: Determinants of Levels of FPI and FDI}

\begin{tabular}{lcccc}
\hline & \multicolumn{2}{c}{ Case 1 (FPI) } & \multicolumn{2}{c}{ Case 2 (FDI) } \\
\hline & Coef & St. err. & Coef & St. err. \\
\hline Log of FPI (one-period lag) & $0.32^{*}$ & 0.04 & & \\
\hline Log of FDI (one-period lag) & & & $0.42^{*}$ & 0.04 \\
\hline Population (log) & -0.71 & 0.84 & 0.67 & 0.67 \\
\hline GDP per capita (log) & $0.98^{*}$ & 0.26 & $0.96^{*}$ & 0.25 \\
\hline Stock market capitalization & $0.18^{*}$ & 0.04 & 0.03 & 0.04 \\
\hline Trade openness (log) & -0.20 & 0.17 & $0.36^{*}$ & 0.16 \\
\hline Probability of liquidity crisis & $-1.53^{*}$ & 0.74 & $-2.33^{*}$ & 0.67 \\
\hline Observations & 613 & & & \\
\hline
\end{tabular}

Note: The dependent variable is the log of FDI stock in Case 1, and the log of FDI stock in Case 2 for 140 source countries over the period from 1985 to 2004 . The estimated probability of liquidity crisis is based on the estimates from Table 3 . All other explanatory variables are from the WDI. A dynamic panel model with country and time fixed effects is estimated. * indicates significance at $5 \%$. 
Table 6: Opacity Index

\begin{tabular}{lccllllll}
\hline Country & Acc & Opa & Country & Acc & Opa & Country & Acc & Opa \\
\hline Finland & 17 & 13 & Argentina & 30 & 44 & Taiwan & 40 & 34 \\
\hline Belgium & 17 & 23 & India & 30 & 48 & Brazil & 40 & 40 \\
\hline Germany & 17 & 25 & Venezuela & 30 & 51 & Poland & 40 & 41 \\
\hline USA & 20 & 21 & UK & 33 & 19 & Russia & 40 & 46 \\
\hline Canada & 20 & 23 & Denmark & 33 & 19 & Egypt & 40 & 48 \\
\hline Chile & 20 & 29 & Hong Kong & 33 & 20 & Czech Rep & 44 & 41 \\
\hline Israel & 20 & 30 & Australia & 33 & 21 & Turkey & 44 & 43 \\
\hline Thailand & 20 & 35 & Austria & 33 & 23 & Lebanon & 44 & 59 \\
\hline Japan & 22 & 28 & S. Africa & 33 & 34 & Singapore & 50 & 24 \\
\hline Indonesia & 22 & 59 & France & 33 & 37 & Spain & 50 & 34 \\
\hline Sweden & 25 & 19 & Mexico & 33 & 44 & Portugal & 50 & 35 \\
\hline Switzerland & 25 & 23 & Pakistan & 33 & 45 & Hungary & 50 & 36 \\
\hline Ecuador & 25 & 42 & Saudi Arabia & 33 & 46 & Greece & 50 & 41 \\
\hline Colombia & 29 & 43 & Philippines & 33 & 50 & China & 56 & 50 \\
\hline Malaysia & 30 & 35 & Netherlands & 38 & 24 & Italy & 63 & 43 \\
\hline Korea & 30 & 37 & Ireland & 38 & 26 & & & \\
\hline
\end{tabular}

Note: The overall Opacity Index was constructed in 2004 by Pricewaterhouse-Coopers. It covers corruption (COR), efficacy of the legal system (LEG), deleterious economic policy (ENF), inadequate accounting and governance practices (ACC), and detrimental regulatory structures (REG). ACC is based on the following survey questions: Have exchanges established disclosure requirements? Are large shareholders required to disclose ownership? Are annual reports available to the public on demand? Are public corporations' financial statements required to be reviewed by an external auditor? Are the country's accounting standards on disclosure in accordance with International Accounting Standards? And must firms account for financial assets at fair market value? The higher is the number, the higher is the opacity. 


\section{Table 7: Determinants of the Ratio of FPI over FDI (The Effect of Opacity)}

\begin{tabular}{lcccc}
\hline & \multicolumn{2}{c}{ Case 1 } & \multicolumn{2}{c}{ Case 2 } \\
\hline & Coef & St. err. & Coef & St. err. \\
\hline Log of FPI/FDI (one-period lag) & & & $0.80^{*}$ & 0.04 \\
\hline Population (log) & $-4.72^{*}$ & 0.71 & $-2.37^{*}$ & 0.78 \\
\hline GDP per capita (log) & $0.69^{*}$ & 0.32 & -0.12 & 0.24 \\
\hline Stock market capitalization & $0.27^{*}$ & 0.07 & 0.004 & 0.04 \\
\hline Trade openness (log) & 0.29 & 0.23 & -0.22 & 0.16 \\
\hline Probability of liquidity crisis & $-16.5^{*}$ & 3.92 & $-8.66^{*}$ & 2.48 \\
\hline Probability of crisis * Opacity & $0.60^{*}$ & 0.11 & $0.24^{*}$ & 0.07 \\
\hline Observations & 510 & & 459 & \\
\hline
\end{tabular}

Note: The dependent variable is the log of FPI stock over FDI stock, for 140 source countries over the period from 1985 to 2004 . The estimated probability of liquidity crisis is based on the estimates from Table 3. All other explanatory variables are from the WDI. Case 1 is the panel estimation with country and year fixed effects. Case 2 adds a one-year-lagged dependent variable as an explanatory variable, and estimates a dynamic panel model. * indicates significance at $5 \%$. 
Table 8: Determinants of the Ratio of FPI over FDI: Nonlinearity

\begin{tabular}{lcccc}
\hline & \multicolumn{2}{c}{ Case 1 } & \multicolumn{2}{c}{ Case 2 } \\
\hline & Coef & St. err. & Coef & St. err. \\
\hline Log of FPI/FDI (one-period lag) & $0.46^{*}$ & 0.04 & 0.47 & 0.04 \\
\hline Population (log) & -2.32 & 1.23 & -2.43 & 1.22 \\
\hline GDP per capita (log) & 0.56 & 0.37 & 0.61 & 0.37 \\
\hline Stock market capitalization & $0.20^{*}$ & 0.06 & 0.21 & 0.06 \\
\hline Trade openness (log) & $-0.68^{*}$ & 0.23 & -0.69 & 0.23 \\
\hline Probability of liquidity crisis & -1.39 & 3.10 & & \\
\hline Probability of liquidity crisis`2 & 17.71 & 9.57 & $13.80^{*}$ & 3.66 \\
\hline Observations & 603 & & 603 & \\
\hline
\end{tabular}

Note: The dependent variable is the log of FPI stock over FDI stock, for 140 source countries over the period from 1985 to 2004 . The estimated probability of liquidity crisis is based on the estimates from Table 3. All other explanatory variables are from the WDI. Country and year fixed effects are included. * indicates significance at $5 \%$. 
Table 9: Episodes of Interest Rate Hike

\begin{tabular}{|c|c|}
\hline Italy & 1992 \\
\hline Norway & 2001,1998, \\
\hline Sweden & 1992 \\
\hline Finland & 1991, \\
\hline Greece & 1992,1987, \\
\hline Iceland & 1991, \\
\hline Ireland & 1990 \\
\hline Malta & 2001,1996 \\
\hline Portugal & 1991,1987 \\
\hline Spain & 1987 \\
\hline Australia & 1989 \\
\hline South Africa & 2003 \\
\hline Argentina & 2001,1995 \\
\hline Brazil & 1998, \\
\hline Chile & $1998,1996,1992,1989$, \\
\hline Colombia & $2001,1998,1995,1987$, \\
\hline Costa Rica & 2000 \\
\hline Dominican Republic & 2002,1998 \\
\hline Mexico & 1998,1995, \\
\hline Paraguay & 2003,2001,1999,1997,1995,1991, \\
\hline Peru & $1997,1991,1990$ \\
\hline Uruguay & $2002,1996,1994,1992,1989$, \\
\hline Venezuela, Rep. Bol. & $2001,1998,1997,1993,1991,1990,1988$, \\
\hline Trinidad and Tobago & $2002,2001,1998,1995$ \\
\hline Bahrain & $2001,1998,1995,1992,1991$, \\
\hline Israel & 2003,1987 \\
\hline Jordan & 1999 \\
\hline Egypt & 2001,1998 \\
\hline Cambodia & 2000,1999 \\
\hline Hong Kong & 1999 \\
\hline India & 1992, \\
\hline Indonesia & 2002 \\
\hline Malaysia & 2001,1999 \\
\hline Philippines & 1992 \\
\hline Singapore & 2001,1998 \\
\hline Thailand & 1999 \\
\hline Angola & 2004 \\
\hline Botswana & 1998, \\
\hline Gabon & $2003,2001,1995$ \\
\hline Kenya & $1998,1997,1994$, \\
\hline Senegal & 1987 \\
\hline Namibia & $2003,1997,1995$ \\
\hline Swaziland & 1996 \\
\hline Togo & 1987, \\
\hline Uganda & 2004, \\
\hline Armenia & 1999, \\
\hline Belarus & $2002,2001,2000$ \\
\hline Bulgaria & 1999,1998, \\
\hline Moldova & $2004,2001,2000,1998,1997$ \\
\hline Russia & $2001,2000,1998$ \\
\hline China,P.R.: Mainland & 1996,1995, \\
\hline Ukraine & $2001,1998,1997,1996$, \\
\hline Czech Republic & 1999,1996, \\
\hline Slovak Republic & 1995,1994, \\
\hline Estonia & $1998,1997,1994$, \\
\hline Hungary & 2004,1992, \\
\hline Lithuania & $1999,1998,1996,1994$, \\
\hline Croatia & 2002 \\
\hline Slovenia & 1996,1994, \\
\hline Macedonia & 2001 \\
\hline Poland & 1996, \\
\hline
\end{tabular}


Table 10: Probit Estimation of Liquidity Crises: Interest Rate Hikes

\begin{tabular}{lcc}
\hline & Coef. & Std. Err. \\
\hline Population $(\log )$ & -0.07 & 0.05 \\
\hline GDP per capita $(\log )$ & -0.06 & 0.10 \\
\hline U.S. real interest rate & $0.19^{*}$ & 0.05 \\
\hline Sovereign rating & $-0.19^{*}$ & 0.06 \\
\hline Constant & 0.17 & 1.24 \\
\hline R-square & 0.11 & \\
\hline Observations & 689 & \\
\hline
\end{tabular}

Note: Table 9 estimates the probability of liquidity crises for 140 countries over the period 1985-2004. The dependent variable is the dummy indicator of liquidity crises defined as a real interest rate rise of more than $4 \%$ a year. Sovereign rating is from Standard and Poor's, while all other variables are from the WDI. A pooled Probit regression is estimated. * indicates significance at $5 \%$. 


\section{Table 11: Determinants of the Ratio of FPI over FDI}

\begin{tabular}{lcccc}
\hline & \multicolumn{2}{c}{ Case 1 } & \multicolumn{2}{c}{ Case 2 } \\
\hline & Coef & St. err. & Coef & St. err. \\
\hline Log of FPI/FDI (one lag) & & & 0.47 & 0.04 \\
\hline Population (log) & $-2.94^{*}$ & 0.76 & $-2.61^{*}$ & 1.22 \\
\hline GDP per capita (log) & 0.29 & 0.34 & 0.52 & 0.37 \\
\hline Stock market capitalization & $0.36^{*}$ & 0.07 & $0.23^{*}$ & 0.06 \\
\hline Trade openness (log) & -0.27 & 0.25 & $-0.68^{*}$ & 0.23 \\
\hline Probability of liquidity crisis & $3.38^{*}$ & 0.88 & $3.06^{*}$ & 0.87 \\
\hline Observations & 697 & & 603 & \\
\hline
\end{tabular}

Note: The dependent variable is the log of FPI stock over FDI stock, for 140 source countries over the period from 1985 to 2004 . The estimated probability of liquidity crisis is based on the estimates from Table 9. All other explanatory variables are from the WDI. Case 1 is the panel estimation with country and year fixed effects. Case 2 adds a one-year-lagged dependent variable as an explanatory variable, and estimates a dynamic panel model. * indicates significance at 5\%. 


\section{Table A.1: Probit Estimation of Currency Crises}

\begin{tabular}{lcc}
\hline & Coef. & Std. Err. \\
\hline Population $(\log )$ & 0.00 & 0.03 \\
\hline GDP per capita $(\log )$ & $-0.11^{*}$ & 0.03 \\
\hline M3/GDP $(\log )$ & -0.05 & 0.04 \\
\hline U.S. real interest rate & $0.06^{*}$ & 0.02 \\
\hline Reserve over imports & $-0.04^{*}$ & 0.02 \\
\hline GDP growth rate & $-3.42^{*}$ & 0.80 \\
\hline Trade openness & $-0.005^{*}$ & 0.002 \\
\hline Constant & -0.40 & 0.64 \\
\hline R-square & 2663 & \\
\hline Observations & 0.07 & \\
\hline
\end{tabular}

Note: Table A.1 estimates the probability of currency crises for 140 countries over the period 1970-2004. The dependent variable is the dummy indicator of currency crises defined as a real exchange rate depreciation of more than $15 \%$ a year. All explanatory variables are from the WDI. A pooled Probit regression is estimated. * indicates significance at $5 \%$. 


\section{Table A.2: Determinants of the Ratio of FPI over FDI}

\begin{tabular}{lccc}
\hline & Case 1 & Case 2 & Case 3 \\
\hline Log of FPI/FDI (one lag) & & $0.74^{*}$ & $0.72^{*}$ \\
& & $(0.03)$ & $(0.03)$ \\
\hline Population (log) & $-0.50^{*}$ & 0.03 & -0.29 \\
& $(0.94)$ & $(0.84)$ & $(0.84)$ \\
\hline GDP per capita (log) & -0.07 & $-0.60^{*}$ & -0.55 \\
& $(0.039$ & $(0.30)$ & $(0.30)$ \\
\hline Stock market capitalization & 0.07 & -0.01 & 0.03 \\
& $(0.05)$ & $(0.04)$ & $(0.04)$ \\
\hline Trade openness (log) & $-0.93^{*}$ & $-0.39^{*}$ & $-0.41^{*}$ \\
& $(0.26)$ & $(0.19)$ & $(0.18)$ \\
\hline Growth rate & $4.32^{*}$ & 1.70 & $1.99^{*}$ \\
& $(11.49)$ & $(1.08)$ & $(0.92)$ \\
\hline Time trend (t) & & & $0.04^{*}$ \\
& & & $(0.02)$ \\
\hline Probability of currency crisis & $7.53^{*}$ & $4.77^{*}$ & $5.78^{*}$ \\
& $(3.41)$ & $(2.41)$ & $(1.83)$ \\
\hline Observations & 752 & 671 & 671 \\
\hline
\end{tabular}

Note: The dependent variable is the log of FPI stock over FDI stock, for 140 source countries over the period from 1990 to 2004. The estimated probability of currency crisis is based on the estimates from Table A.1. All other explanatory variables are from the WDI. Case 1 is the panel estimation with country and year fixed effects. Case 2 adds a one-year-lagged dependent variable as an explanatory variable, and estimates a dynamic panel model. Case 3 replaces the year fixed effects in Case 2 with a time trend. Standard errors are in parentheses. $*$ indicates significance at $5 \%$. 